\title{
Safety Consequences of Off-Label Drugs Used for COVID-19
}

\author{
Nabarun Dasgupta ${ }^{1}$ \\ Accepted: 5 February 2021 / Published online: 5 March 2021 \\ (c) The Author(s), under exclusive licence to Springer Nature Switzerland AG part of Springer Nature 2021
}

\section{Addressing Two Safety Concerns}

During a global emergency, making clever use of existing resources is a fundamental human impulse. The cavalier repurposing of hydroxychloroquine, chloroquine, and azithromycin during the coronavirus disease 2019 (COVID-19) pandemic may have consequences [1], and not only have clinical trials decisively shown that these particular drugs lack effectiveness in this disease $[2,3]$ but Beyzarov et al. [4] have also provided empirical evidence of safety-related harms. Therefore, we would be wise to read this study in the context of a well-intentioned but tragically flawed global scramble for cures for COVID-19. We must also address the resulting misinformation.

The study by Beyzarov et al. [4] evaluates two questions of considerable importance to public health. The first is, "What are the consequences of off-label use of drugs such as hydroxychloroquine and azithromycin when treating COVID-19?"

Seven deaths from cardiac adverse events occurred with the off-label use of drugs whose power to prevent COVID-19 has been discredited. We now glimpse the tip of the iceberg amid a sea of well-intentioned but unsubstantiated promotion. More cases have certainly occurred.

The second question is, "Can medications predispose one to an increased risk of severe acute respiratory syndrome coronavirus 2 (SARS-CoV-2) infection or full-blown disease?" Beyzarov et al. [4] presented a compelling hypothesis that some immunosuppressive treatments may increase the risk of developing fulminant COVID-19. Among the 353 cases of emergent COVID-19, the most common were patients undergoing therapy for rheumatoid arthritis. This does have implications for vaccination priority, but

Nabarun Dasgupta

nab@unc.edu

1 Gillings School of Global Public Health, University of North Carolina at Chapel Hill, Chapel Hill, NC, USA medication-mediated susceptibility to SARS-CoV-2 infection needs to be evaluated systematically.

A narrow view from pharmacology might suggest that answers to both of these questions were anticipated based solely on molecular mechanisms: the side effects are known, and immunosuppression is predictable [1]. Yet, real-world data are imperative, and Beyzarov et al. [4] provide muchneeded empirical evidence. They do not overstate their data, and in the discussion they lay out careful logic supporting their hypotheses.

\section{About the Study}

The data come from a real-time global database of side effect reports that each pharmaceutical company is legally required to maintain. The Pfizer database used in this study receives around half a million reports each year. General interest and prescribing frequency both strongly influenced reporting volume during the pandemic, as demonstrated in Fig. 1 in Beyzarov et al. [4]. Each report was medically assessed to establish the strength of the causal connection between the medication and the reported side effect. They presented 1508 cases gathered during the first 8 months of the pandemic, mainly involving immunosuppressant/immunomodulating agents and anticoagulant/antithrombic agents, as well as corticosteroids.

\section{Global Context}

Azithromycin is routinely used to treat bacterial respiratory infections; hydroxychloroquine can prevent malaria and help manage autoimmune diseases. They are widely available and have been in use for a long time. Both these factors contributed to perceptions of safety among the public and medical professionals. In February 2020, based on small uncontrolled case series or trials, these medications were put forward for "compassionate use" to arrest mortality from COVID-19 [5-7]. In parallel, prevention of SARS-CoV-2 
infection was widely inferred, despite a lack of supporting evidence.

The results were immediate and global in scale: Many governments authorized emergency use. By April 2020, 56\% of surveyed Indian anesthesiologists had taken hydroxychloroquine as a preventative [8], and the USA saw an 80-fold increase in prescribing [9]. Pharmacies in Moscow sold out of chloroquine and hydroxychloroquine [10], and patients with autoimmune diseases in Indonesia feared being cut-off from essential medications [11]. In Nigeria, three patients were hospitalized with poisoning from self-medication [12]. Each country reacted differently to the swirling winds of misinformation: Kenya banned pharmacy sales, and Tunisia started domestic production [12]. Physicians in the United Arab Emirates [13], Saudi Arabia [14], and Canada [15] publicly struggled with whether to recommend these medicines, with many deciding against it.

The World Health Organization stepped in. Starting in March 2020, the Solidarity trial enrolled 11,330 patients in 30 countries to evaluate four drugs repurposed to prevent in-hospital mortality among patients with COVID-19: remdesivir, hydroxychloroquine, lopinavir, and interferon $\beta-1 \mathrm{a}$ [3]. Between June and October 2020, each arm of the study was discontinued for futility. By late 2020, most major drug regulators had revoked the emergency use authorization and warned against the use of these drugs in the treatment of COVID-19 in hospitalized patients. At the same time, trials with dexamethasone were showing promising results, tempering the salience of other repurposing experiments. In short, no other cohort of medications in recent history has changed medical practice so rapidly. Beyzarov et al. [4] have provided a glimpse into how global pharmacovigilance systems responded to this unfolding saga.

\section{Off-Label Use}

In the paper by Beyzarov et al. [4], 842 cases reported offlabel use for COVID-19-specific indications. In these cases, various antimicrobials (e.g., antibiotics, antiretrovirals, antivirals) and other supportive therapy (e.g., corticosteroids, immunoglobulin) were employed [4]. In total, 120 reports included long-QT syndrome, tachycardia, sudden death, and cardiac arrest. In seven cases, the cardiac complications resulted in death.

Also interesting is what went unobserved. Many of the antimicrobials studied can disrupt glycemic control (e.g., glucose lowering by hydroxychloroquine). Yet these issues were barely reported, swamped as they were by cardiac events. We cannot dismiss the possibility of stimulated reporting.

When reading the work by Beyzarov et al. [4], it is worth considering a few caveats. One-third of all off-label use reports came from France. Despite the global scope of the database, reports were most frequently from the USA, France, and Spain and may not be globally representative. Most of the adverse events involved concomitant use of multiple medications, making it inherently difficult to disentangle individual drug effects. Half of the patients had underlying conditions that might predispose them to infection or the negative consequences of infection. One in three patients were aged $\geq 65$ years, but only $1.5 \%$ were children, although age was not reported in all cases. Little information on dose was available [16]. These caveats suggest that other databases $[17,18]$ will be required beyond those of manufacturers to achieve a complete global picture.

One limitation of the Beyzarov et al. [4] study is that it was not designed to assess adverse events among those taking azithromycin and/or hydroxychloroquine to prevent SARS-CoV-2 infection. Vaccine clinical trials have focused on preventing COVID-19 progression and mortality, leaving a knowledge gap when it comes to prevention of transmission. Real-world clinical encounter data might be suited to identify consequences of off-label use in patients taking these drugs without a diagnosis of a labeled indication.

Reporting on off-label use carries risks for pharmaceutical companies. Beyzarov et al. [4] have done a commendable job of presenting factual findings in the context of what is known, in a responsible fashion. Deaths from off-label use can sometimes provoke mandatory risk management. There is room for debate about the necessity of enacting more coercive measures, such as the pharmacy ban in Kenya. However, beyond formal risk management, safety communication has an immediate and challenging role to play.

\section{Was It Misinformation?}

Within the swirling mass of digital communication, both whimsical pseudoscientific notions and well-reasoned hypotheses have the opportunity to find purchase. In hindsight, the underlying evidence for repurposing these specific drugs was flawed. Other antimicrobials have also been touted [19]. But while clinical trials were ongoing, would it have been fair to label lay media promotion of these drugs as misinformation? When does off-label use go from being a rational clinical decision to an unjustifiable risk?

We can point to 19 June 2020 , when the hydroxychloroquine arm of the Solidarity trial was halted [3]. Our responsibility may appear to end when we support fact checkers by generating that novel kernel of evidence. "Exposure to misinformation cannot simply be undone through fact checking, correcting, or debunking efforts: a large body of research has shown that [social media] retractions are rarely successful at eliminating reliance on misinformation, a phenomenon known as the "continued 
influence' effect" [20]. Yet, it is unclear who bears the broader responsibility to develop alternative strategies.

What can be done when the other side wields a bullhorn against professionally cautious scientific voices? Drawing from vaccine misinformation research, a handful of recent studies offer hope and guideposts.

First, health misinformation on Twitter is not driven solely by bots [21], though the evidence is mixed [22, 23]. Second, misinformation becomes indelible when vaccineamenable and anti-vaccination clusters interact. Taken together, there is growing consensus that targeting efforts to specific subgroups may have an outsized impact [24]. The surveys of physicians cited earlier offer clues. On an individual patient level, there is evidence to recommend a subtle shift towards offering patients assistance in decision making rather than attempting to persuade directly or discredit specific information sources [25]. As healthcare professionals, we have underutilized structural advantages to counter the false equivalency of authority. Stated more plainly: Patients will be more likely to listen to us when we acknowledge their autonomy, even if we are the ones prescribing the medication [26]. Finally, it has been noted that pro-vaccination conversations tend to be monothematic. In contrast, anti-vaccination conversations in social media tend to include alternative medicine, etiology, and a host of other topics [24]. Broadening the scope of discussion while maintaining the intent seems promising, even though it requires a more wholistic discussion than pharmacovigilance experts usually see as their remit. For example, many chloroquine advocates mobilize conspiracy theories to defend this treatment, arguing that pharmaceutical companies are willing to discredit it because it would jeopardize potential profits from more expensive medications [27]. Our collective reticence to dismiss or avoid such uncomfortable topics may be obscuring opportunities for patient engagement. These insights and others [28] serve as a starting point to guide us towards a higher public profile for pharmacovigilance [29].

\section{Conclusions}

The zeal of repurposing stems from a human desire to find solutions with tools that already exist. The swiftness of the progression from case series to randomized trials and dismissal has been unprecedented. Summary descriptions such as that by Beyzarov et al. [4] are vital. They encapsulate real-time, high-volume information to help clinicians make decisions. Through pandemic response, we have the opportunity to raise the profile of pharmacovigilance, but this may require us to step out of our professional comfort zones.

\section{Declarations}

Funding No sources of funding were used to conduct this study or prepare this manuscript.

Conflicts of interest Nabarun Dasgupta has no conflicts of interest that are directly relevant to the content of this article.

Ethics approval Not applicable.

Consent to participate Not applicable.

Consent for publication Not applicable.

Availability of data and materials Not applicable.

Code availability Not applicable.

Author contributions Nabarun Dasgupta wrote this article in its entirety and approved the final version.

\section{References}

1. Kalil AC. Treating COVID-19-off-label drug use, compassionate use, and randomized clinical trials during pandemics. JAMA. 2020;323:1897.

2. Mitjà $\mathrm{O}$, Corbacho-Monné $\mathrm{M}$, Ubals $\mathrm{M}$, Tebé $\mathrm{C}$, Peñafiel J, Tobias A, et al. Hydroxychloroquine for early treatment of adults with mild Covid-19: a randomized-controlled trial. Clin Infect Dis. Epub 16 July 2020. https://doi.org/10.1093/cid/ciaa1009/58725 89.

3. WHO Solidarity Trial Consortium. Repurposed antiviral drugs for Covid-19-Interim WHO Solidarity Trial results. N Engl J Med. Epub 2 December 2020. https://doi.org/10.1056/nejmoa2023184.

4. Beyzarov E, Chen Y, Julg R, Naim K, Shah J, Gregory WW, et al. Global safety database summary of COVID-19-related drug utilization-safety surveillance: a sponsor's perspective. Drug Saf. 2021;44(1):95-105. https://doi.org/10.1007/s40264-020-01035-x.

5. Gautret P, Lagier J-C, Parola P, Hoang VT, Meddeb L, Mailhe $\mathrm{M}$, et al. Hydroxychloroquine and azithromycin as a treatment of COVID-19: results of an open-label non-randomized clinical trial. Int J Antimicrob Agents. 2020;56(1):105949. https://doi. org/10.1016/j.ijantimicag.2020.105949.

6. Lagier J-C, Million M, Gautret P, Colson P, Cortaredona S, Giraud-Gatineau A, et al. Outcomes of 3,737 COVID-19 patients treated with hydroxychloroquine/azithromycin and other regimens in Marseille, France: a retrospective analysis. Travel Med Infect Dis. 2020;36:101791. https://doi.org/10.1016/j.tmaid.2020.10179 1.

7. Sultana J, Cutroneo PM, Crisafulli S, Puglisi G, Caramori G, Trifirò G. Azithromycin in COVID-19 patients: pharmacological mechanism, clinical evidence and prescribing guidelines. Drug Saf. 2020;43:691-8.

8. Shah S, Pahade A, Chawla R. The COVID-19 hydroxychloroquine prophylaxis perception of Indian anesthesiologists: a survey-based original article. J Anaesthesiol Clin Pharmacol. 2020;36(4):471-6.

9. Bull-Otterson L, Gray EB, Budnitz DS, Strosnider HM, Schieber LZ, Courtney J, et al. Hydroxychloroquine and chloroquine prescribing patterns by provider specialty following initial reports of potential benefit for COVID-19 Treatment-United 
States, January-June 2020. MMWR Morb Mortal Wkly Rep. 2020;69:1210-5.

10. Moiseev S, Avdeev S, Brovko M, Novikov P, Fomin V. Is there a future for hydroxychloroquine/chloroquine in prevention of SARS-CoV-2 infection (COVID-19)? Ann Rheum Dis. 2021;80(2):e19. https://doi.org/10.1136/annrheumdis-2020-21757 0 .

11. Widhani A, Rengganis I, Susanto AJ, Surachmanto EE, Hasibuan AS, Fetarayani D, et al. Factors related to knowledge, perception, and practices towards COVID-19 among patients with autoimmune diseases: a multicenter online survey. Acta Med Indones. 2020;52(3):214-26.

12. Belayneh A. Off-label use of chloroquine and hydroxychloroquine for COVID-19 treatment in Africa against WHO recommendation. Res Rep Trop Med. 2020;11:61-72.

13. AlAkhras A, AlMessabi AH, Abuzeid H, Khoo S, Nsutebu EF. Use of specific antimicrobials for COVID-19: should we prescribe them now or wait for more evidence? Postgrad Med J. 2020;96:377-8.

14. Mallhi TH, Khan YH, Alotaibi NH, Alzarea AI, Alanazi AS, Qasim S, et al. Drug repurposing for COVID-19: a potential threat of self-medication and controlling measures. Postgrad Med J. Epub 26 Aug 2020. https://doi.org/10.1136/postgradmedj-2020138447.

15. Juurlink DN. Safety considerations with chloroquine, hydroxychloroquine and azithromycin in the management of SARS-CoV-2 infection. CMAJ. 2020;192(17):E450-3. https://doi.org/10.1503/ cmaj.200528.

16. Bénézit F, Le Bot A, Jouneau S, Lemaître F, Pronier C, Lentz P-A, et al. COVID-19 in patient with sarcoidosis receiving long-term hydroxychloroquine treatment, France, 2020. Emerg Infect Dis. 2020;26:2513-5.

17. Zekarias A, Watson S, Vidlin SH, Grundmark B. Sex differences in reported adverse drug reactions to COVID-19 drugs in a global database of individual case safety reports. Drug Saf. 2020;43:1309-14.

18. Garcia P, Revet A, Yrondi A, Rousseau V, Degboe Y, Montastruc F. Psychiatric disorders and hydroxychloroquine for coronavirus disease 2019 (COVID-19): a VigiBase study. Drug Saf. 2020;43:1315-22.

19. Tuccori M, Convertino I, Ferraro S, Cappello E, Valdiserra G, Focosi D, et al. The impact of the COVID-19 "infodemic" on drug-utilization behaviors: implications for pharmacovigilance. Drug Saf. 2020;43:699-709.

20. Vanderpool RC, Gaysynsky A, Sylvia Chou W-Y. Using a global pandemic as a teachable moment to promote vaccine literacy and build resilience to misinformation. Am J Public Health. 2020;110:S284-5.

21. Dunn AG, Surian D, Dalmazzo J, Rezazadegan D, Steffens M, Dyda A, et al. Limited role of bots in spreading vaccine-critical information among active twitter users in the United States: 2017 2019. Am J Public Health. 2020;110:S319-25.

22. Broniatowski DA, Jamison AM, Qi S, AlKulaib L, Chen T, Benton A, et al. Weaponized health communication: twitter bots and russian trolls amplify the vaccine debate. Am J Public Health. 2018;108:1378-84.

23. Shao C, Ciampaglia GL, Varol O, Yang K-C, Flammini A, Menczer F. The spread of low-credibility content by social bots. Nat Commun. 2018;9:4787.

24. Johnson NF, Velásquez N, Restrepo NJ, Leahy R, Gabriel N, El Oud S, et al. The online competition between pro- and anti-vaccination views. Nature. 2020;582:230-3.

25. Leask J, Kinnersley P, Jackson C, Cheater F, Bedford H, Rowles G. Communicating with parents about vaccination: a framework for health professionals. BMC Pediatr. 2012;12:154. https://doi. org/10.1186/1471-2431-12-154.

26. Ho EP, Neo H-Y. COVID 19: prioritise autonomy, beneficence and conversations before score-based triage. Age Ageing. 2021;50(1):11-5. https://doi.org/10.1093/ageing/afaa205/59089 95.

27. Bertin P, Nera K, Delouvée S. Conspiracy beliefs, rejection of vaccination, and support for hydroxychloroquine: a conceptual replication-extension in the COVID-19 pandemic context. Front Psychol. 2020;11:565128. https://doi.org/10.3389/fpsyg .2020.565128/full.

28. Sylvia Chou W-Y, Gaysynsky A. A prologue to the special issue: health misinformation on social media. Am J Public Health. 2020;110:S270-2.

29. Chandler RE, McCarthy D, Delumeau J-C, Harrison-Woolrych $\mathrm{M}$. The role of pharmacovigilance and ISoP during the global COVID-19 pandemic. Drug Saf. 2020;43:511-2. 